\title{
Comparing the Effect of a Jump Rope Training on Physical and Motor Fitness Components Among Primary School Boy and Girl Students
}

\author{
Amir Hossein Haghighi ${ }^{1 *}$, Javad Cheraghian² ${ }^{2}$ Mohammad Reza Hamedinia ${ }^{3}$ and Javad Harati ${ }^{4}$ \\ ${ }^{1}$ Associate Professor of Exercise Physiology, Faculty of Sport Sciences, Hakim Sabzevari University, Sabzevar, Iran \\ ${ }^{2}$ MS in Exercise Physiology, Hakim Sabzevari University, Sabzevar, Iran
}

${ }^{3}$ Professor of Exercise Physiology, Faculty of Sport Sciences, Hakim Sabzevari University, Sabzevar, Iran

${ }^{4} \mathrm{MS}$ in Corrective Exercises and Sports injuries, Hakim Sabzevari University, Sabzevar, Iran

Submission: April 06, 2018; Published: April 23, 2018

*Corresponding author: Amir Hossein Haghighi, Associate Professor of Exercise Physiology, Faculty of Sport Sciences, Hakim Sabzevari University, Sabzevar, Iran; Tel: +98 514 440-12765; E-mail: ah.haghighi@hsu.ac.ir

\begin{abstract}
Different types of training methods can affect children's physical fitness as well as performance in different ways. The aim of this study was to compare the effect of jump rope training on some of the physical and motor fitness factors between male and female primary school students. Forty-three male and female students from primary school volunteered. The students participated in a jump rope training program for 6 weeks ( 3 sessions per week). Before and after the training periods physical and motor fitness tests including cardiovascular endurance, agility, speed, legs explosive power, hands muscle endurance, hands power, static and dynamic balance were taken from the participants. The data were analyzed using the ANCOVA and dependent T-tests at a significance level of $\mathrm{P}<0.05$. The results showed no significant difference between male and female students in the indices of cardiovascular endurance, speed, hands muscular endurance, hands muscle power, legs explosive power, static and dynamic balance $(\mathrm{P}>0.05)$, while the agility index was improved in male students. It is suggested that male and female primary school students use Jump Rope trainings to improve their physical fitness and motor factors.
\end{abstract}

Keywords : Balance; Cardiovascular endurance; Jump rope training; Student

\section{Introduction}

In terms of general health, physical fitness is one of the important concepts in childhood and adolescence. Low physical fitness in childhood and adolescence is associated with overall mortality, cardiovascular diseases, and type 2 diabetes in adulthood. On the other hand, it has been shown that people with high physical fitness, have a longer life span and are less prone to illness [1]. One of the skill exercises that increases physical fitness is jump rope. Jump rope allows students to maximize their physical activity in the least span of time and in smallest of spaces with almost no expensive equipment. Jump rope training, due to its diversity, affects the infrastructural factors of different dimensions of perceptual-motor abilities and can play a significant role in improving and developing balance, coordination and agility of students, if properly and appropriately practiced [2]. In this regard, Campbell [3] states that jumping exercises with rope is a valuable activity that results in muscle strength and endurance, cardiovascular health, balance, agility, and coordination between body organs [3]. On the other hand, the results of various researches indicate that gender is an effective factor in the implementation of basic motor skills [4-8]. Generally, experts believe that boys are superior to girls in most motor skills. The fact that boys are more active than girls is a relatively accepted finding. However, the extent to which gender make differences seems to depend on the type and intensity of activity [9].

Nevertheless, despite the overall decline in physical activity in both genders, gender differences in physical activity continue to increase until the late stages of childhood, adolescence and adulthood, so that boys prove superior to girls, on average, in engaging with physical activities. This can be attributed to the fact that boys spend more time in moderate-level activities than girls with regard to gender composition and type of sports [10]. However, since the Ministry of Education's new curriculum compelled to include a jump rope plan (Tanavarz) for elementary education, it seems necessary to investigate the impact of this physical activity on the students' physical and motor fitness along with the importance of implementing this plan according to gender. Considering that literature in this area had been 
conducted at higher age levels, and only few indices have been surveyed in them [11-13], and also the fact that studies in the lower age levels have limited themselves to a single gender [1416], the purpose of this study is to compare the effect of a jump rope training course on physical and motor fitness components in boys and girls primary school students.

\section{Materials and Methods}

\section{Participants and Study Design}

The research method was quasi-experimental and fieldbased with pre-test and post-test design. The statistical sample included 21 male students and 22 female primary school students (2nd, 4 th and 6 th grade) in the city of Sabzevar with a range of 8 to 12 years old who were selected as available samples. At first, subjects and their parents signed a written consent and were informed about the risks and benefits of the present study which was approved by the Ethical Committee of the Department of Sport Sciences, University of Hakim Sabzevari. Also, according to the questionnaire for assessing the readiness to start physical activity, people with a record of diseases were excluded. In addition, to act more assuredly, a health certificate was given to selected samples for visiting a doctor, and students who were not in desirable levels of physical and mental health, as well as those who were not interested in taking part in the research project, were cancelled out from the list. Also, the subjects were not members of any particular sports team or club, and they just followed the jump rope training.

\section{Training Program}

The jump rope program was run for six weeks (three sessions a week). In order to get acquainted with the training and also more physical fitness of the subjects, students were trained with different methods of jump rope for two weeks before the pretest, and finally, the jump rope run in place was selected as a training method for the subjects. The training program started with five one-minute sets and ended with fourteen one-minute sets. The resting time between sets was one minute. The jumping rhythm was 60 times per minute, which was controlled by the intensity and the overload of the training along with the tonality and with increasing number of sets per week (Table 1).

Table 1: Jump rope training program.

\section{Physical and Motor Fitness Tests}

The shuttle run test was used to measure cardiovascular endurance [17], T test for measuring agility [18], 20-meter sprint test to measure speed, Vertical Jump test (Sargent Jump test) to measure legs explosive power, modified chin-up to measure the muscular endurance of the hands [18], throwing a one and a half kilogram medicine ball to measure the power of the hands [19], Standing Stork Test for static balance measurements, and Y balance test for dynamic balance measurements [20]. Also, the height of the subjects was measured using tape measure and weight using the Seca scale made in Germany.

\section{Statistical Analysis}

The Shapiro-Wilk test was used to check the normal distribution of data. Independent t-test and covariance analysis were used to examine the between-group changes. In order to investigate within-group changes, the paired Student's t-tests were used. All of the statistical tests were performed using SPSS software version 16 and a significant level of $p<0.05$ was considered.

\section{Results}

Using the Shapiro-Wilk test, it was found out that the distribution of all variables in the research is normal, so parametric tests were used to perform statistical computations (Table 2). The results of statistical operations on the measures of Table 1 showed that there was no significant difference in body weight, agility, legs explosive power, hand power, static balance and dynamic balance indices between two groups of boys and girls $(\mathrm{p}>0.05)$. But, there was a significant difference in the cardiovascular endurance, muscle strength and muscle endurance indices between the two groups ( $p>0.05$ ). Also, the result of the covariance analysis test on the post test results of Table 1 indices showed that there was no significant difference between the two groups in cardiovascular endurance $(\mathrm{p}=0.39$, $\mathrm{F}=73.0$ ). Within-group outcomes showed that cardiovascular endurance in boys was significantly increased $(t=0.86, p=0.03)$. However, there was no significant change in the girls group $(\mathrm{p}=0.92, \mathrm{t}=-1.43)$.

\begin{tabular}{|c|c|c|c|c|}
\hline Week & Exercise & Total Session Time (Min) & Rest Between Sets & Intensity (Jump.minutes) \\
\hline $1 \mathrm{st}$ & 5 sets of 1 minute & 10 & \multirow{5}{*}{$1 \mathrm{~min}$} & \multirow{5}{*}{60} \\
\hline 2nd & 6 sets of 1 minute & 12 & & \\
\hline 3rd & 8 sets of 1 minute & 16 & & \\
\hline 4 th & 10 sets of 1 minute & 20 & & \\
\hline 5th & 12 sets of 1 minute & 24 & & \\
\hline
\end{tabular}


Journal of Physical Fitness, Medicine \& Treatment in Sports

Table 2: Results of statistical tests on research measures in pre-test and post-test stages in experimental groups.

\begin{tabular}{|c|c|c|c|c|c|c|c|}
\hline \multirow[b]{2}{*}{ Test } & \multirow[b]{2}{*}{ Groups } & \multicolumn{2}{|c|}{ Measuring Variables } & \multirow[b]{2}{*}{ (Pre-test) P } & \multirow{2}{*}{$\begin{array}{l}\text { P Value Intra- } \\
\text { group }\end{array}$} & \multirow[b]{2}{*}{ t Value } & \multirow{2}{*}{$\begin{array}{l}\text { P Value } \\
\text { Between- } \\
\text { Group }\end{array}$} \\
\hline & & $\begin{array}{l}\text { Pre-Test } \\
(\mathrm{M} \pm \mathrm{SD})\end{array}$ & $\begin{array}{l}\text { Post-Test } \\
(\mathrm{M} \pm \mathrm{SD})\end{array}$ & & & & \\
\hline \multirow{2}{*}{$\begin{array}{c}\text { Cardiovascular } \\
\text { endurance }(\mathrm{ml} / \mathrm{kg})\end{array}$} & Boys & $58.80 \pm 1.84$ & $59.35 \pm 1.80$ & \multirow{2}{*}{$*_{0}^{*} 0001$} & $*^{*} 0.03$ & -1.86 & \multirow{2}{*}{0.39} \\
\hline & Girls & $54.39 \pm 2.18$ & $54.40 \pm 2.69$ & & 0.092 & -1.43 & \\
\hline \multirow{2}{*}{ Speed (s) } & Boys & $3.97 \pm .030$ & $4.05 \pm 0.32$ & \multirow{2}{*}{$* 0.0001$} & 0.1 & -1.7 & \multirow{2}{*}{0.12} \\
\hline & Girls & $4.43 \pm 0.36$ & $4.26 \pm 0.31$ & & $* 0.0001$ & 5.14 & \\
\hline \multirow{2}{*}{ Agility (s) } & Boys & $15.40 \pm 1.41$ & $14.95 \pm 1.51$ & \multirow{2}{*}{0.17} & 0.05 & 2 & \multirow{2}{*}{$*_{0}^{*} 0.03$} \\
\hline & Girls & $16.08 \pm 1.77$ & $16.12 \pm 1.65$ & & 0.82 & -0.22 & \\
\hline \multirow{2}{*}{$\begin{array}{l}\text { Hands muscular } \\
\text { endurance (reps) }\end{array}$} & Boys & $9.14 \pm 4.70$ & $11.33 \pm 6.20$ & \multirow{2}{*}{$* 0.0001$} & $*^{*} 0.01$ & -2.56 & \multirow{2}{*}{0.69} \\
\hline & Girls & $2.59 \pm 2.21$ & $4.09 \pm 3.10$ & & $* 0.003$ & $40 / 3-$ & \\
\hline \multirow{2}{*}{$\begin{array}{c}\text { Legs Explosive } \\
\text { Power Legs(Watts) }\end{array}$} & Boys & $1793 / 0 \pm 333.39$ & $2377.8 \pm 333.51$ & \multirow{2}{*}{0.54} & ${ }^{*} 0.02$ & -2.44 & \multirow{2}{*}{0.79} \\
\hline & Girls & $2756.5 \pm 630.33$ & $3433.4 \pm 671.90$ & & $*_{0}^{*} 0.01$ & -2.59 & \\
\hline \multirow{2}{*}{ Hands power $(\mathrm{cm})$} & Boys & $296 \pm 62.66$ & $321 \pm 64.74$ & \multirow{2}{*}{0.15} & $* 0.001$ & -4.28 & \multirow{2}{*}{0.85} \\
\hline & Girls & $266 \pm 69.15$ & $294 \pm 73.21$ & & $* 0.001$ & -4.36 & \\
\hline \multirow{2}{*}{$\begin{array}{l}\text { Static Balance } \\
\text { (min) }\end{array}$} & Boys & $3.87 \pm 4.22$ & $4.77 \pm 6.29$ & \multirow{2}{*}{0.42} & 0.9 & -2.88 & \multirow{2}{*}{0.14} \\
\hline & Girls & $6.05 \pm 14.68$ & $8.48 \pm 15.22$ & & 0.45 & -0.75 & \\
\hline \multirow{2}{*}{$\begin{array}{l}\text { Dynamic balance } \\
\text { (anterior/cm) }\end{array}$} & Boys & $77.08 \pm 6.58$ & $82.10 \pm 6.70$ & \multirow{2}{*}{0.05} & ${ }^{*} 0.02$ & -2.38 & \multirow{2}{*}{0.47} \\
\hline & Girls & $73.05 \pm 6.69$ & $76.79 \pm 7.45$ & & $01 / 0^{*}$ & $58 / 2-$ & \\
\hline \multirow{2}{*}{$\begin{array}{c}\text { Dynamic balance } \\
\text { (posterolateral/ } \\
\mathrm{cm} \text { ) }\end{array}$} & Boys & $78.21 \pm 13.12$ & $84.04 \pm 9.55$ & \multirow{2}{*}{0.02} & $* 0.003$ & -0.99 & \\
\hline & Girls & $73.80 \pm 8.45$ & $76.90 \pm 9.98$ & & $* 0.04$ & -1.31 & 0.24 \\
\hline Dynamic balance & Boys & $87.89 \pm 12.43$ & $90.31 \pm 11.38$ & & $* 0.02$ & -1.22 & \\
\hline $\begin{array}{l}\text { (posteromedial/ } \\
\text { cm) }\end{array}$ & Girls & $77.70 \pm 9.63$ & $84.64 \pm 8.24$ & 0.4 & $* 0.0001$ & -4.38 & 0.19 \\
\hline Whiobt llo & Boys & $29.91 \pm 5.43$ & $29.98 \pm 5.58$ & $0 ? 2$ & 0.53 & 0.63 & 07 \\
\hline Weignt (kg) & Girls & $33.47 \pm 11.59$ & $33.23 \pm 11.26$ & 0.22 & 0.16 & -1.43 & 0.19 \\
\hline
\end{tabular}

Significance level: $p \leq 0.05^{*}$

There was no significant difference between the two groups regarding speed index $(\mathrm{p}=0.12, \mathrm{~F}=0.35)$. Within-group results showed no significant change in boys speed $(\mathrm{p}=0.1$, $\mathrm{t}=1.70$ ). However, there was a significant increase in the girls group ( $\mathrm{p}=0.001, \mathrm{t}=5.14)$. The agility index showed a significant difference between two groups, so that jump rope training significantly improved the agility in the boys compared to the girls $(p=0.03, F=4.7)$. There was no significant differences in hands muscular endurance between the two groups $(\mathrm{P}=0.69$, $\mathrm{F}=0.15)$. Within-group outcomes revealed that this index was significantly increased in both boys $(\mathrm{P}=0.01, \mathrm{t}=-2.56)$ and girls $(\mathrm{P}=0.003, \mathrm{t}=-3.40)$. The legs explosive power indicate no significant differences in the two groups $(\mathrm{P}=0.79, \mathrm{~F}=0.009)$. Within-group outcomes revealed that this index was significantly increased in both boys $(\mathrm{P}=0.02, \mathrm{t}=-2.44)$ and girls $(\mathrm{P}=0.01$, $\mathrm{t}$ $=-2.59$ ).

There was also no significant difference in the two groups for muscular power of the hands $(\mathrm{P}=0.85, \mathrm{~F}=0.03)$. Withingroup outcomes revealed that this index was significantly increased in both boys $(\mathrm{p}=0.001, \mathrm{t}=-4.28)$ and girls $(\mathrm{p}=0.001$, $t=-4.36)$. No significant differences were observed in the static balance between the two groups ( $\mathrm{p}=0.14, \mathrm{~F}=2.26$ ). Within-group outcomes indicated that this index was not significantly different in both boys $(\mathrm{P}=0.09, \mathrm{t}=-2.88)$ and girls $(\mathrm{P}=0.45, \mathrm{t}=-0.75)$. Dynamic balance in three directions of the anterior $(\mathrm{P}=0.47$, $\mathrm{F}=0.51)$, posterolateral $(\mathrm{F}=1.38, \mathrm{P}=0.24)$ and posteromedial $(\mathrm{F}=1.73, \mathrm{P}=0.19)$ did not show significant differences between the two groups. Within-group outcomes showed that this index increased significantly in both boys and girls. Body weight did not show significant difference between two groups $(\mathrm{p}=0.79, \mathrm{~F}=$ $0.64)$. Within-group results indicated that body weight in both boys $(\mathrm{P}=0.53, \mathrm{t}=-0.63)$ and girls were not significantly different $(\mathrm{P}=.16, \mathrm{t}=-1.43)$.

\section{Discussion}

The results of this study indicated that there is no significant difference between boys and girls in relation to changes in cardiovascular endurance $\left(\mathrm{VO}_{2 \max }\right)$ due to jumping rope training. Within-group results showed that jumping rope training in boys causes a significant improvement in $\mathrm{VO}_{2 \max }$. But there was no significant change in the girls group. Quite pertinently, Roland et al. [21] found no significant difference between $\mathrm{VO}_{2 \max }$ in girls and boys aged 10 to 13 years-old who were subjected to 
12-week aerobic training (jumping rope, basketball dribbling, shot on goal, etc.). Obert et al. [22] also proved that there was no significant difference between the $\mathrm{VO}_{2 \max }$ of children aged 10 to 11 who had 13 weeks of aerobic training (school curriculum). The researchers stated that boys and girls had the same initial levels of aerobic fitness before puberty in response to $\mathrm{VO}_{2 \max }$ in aerobic exercises which is not affected by gender. In contrast, Doris [6] showed that eight weeks of jump rope training in children aged 9 to 10 would significantly improve the $\mathrm{VO}_{2 \max }$ much more in boys than in girls. The researcher claimed the difference in the concentration of hemoglobin and body composition as a reason for such a result.

Several biologic variables have significant roles in determining the different levels of $\mathrm{VO}_{2 \max }$ in girls and boys. These include higher muscle mass and lower fat mass in boys, high levels of testosterone, and more protein synthesis in boys and high levels of estrogen and more fat synthesis in girls [23]. Wilford et al. [24] reported that high mass of body fat increased heart beat rate and blood pressure during exercise and reduced cardio respiratory endurance. Also, girls have a smaller heart and less stroke volume, which is associated with a smaller body size and possibly lower testosterone levels [25]. Girls' lower capacity for increasing the difference in arterial-venous blood, which is due to lower hemoglobin levels, reduces the ability to carry oxygen to active muscles. Also, among the reasons for difference in $\mathrm{VO}_{2 \max }$ in girls and boys, may be the faster pulse rates of women's heart and their smaller chest when compared to men [26].

The results of this study showed that there is no significant difference between boys and girls in relation to speed variation due to jump rope training. But Within-group results indicated that jump rope training in girls caused a significant improvement of speed. In this regard, Miyaguchi et al. [8] assessed the relationship between jump rope training and speed performance in 5th and 6th grade primary school students. The results showed that boys were better than girls in speed tests. In this research, a double under method (one jump and double under) was used, which may be the reason of inconsistency with the present research. Also, Sohrabi Jahromi, Gholami [16] showed that 15 -week jump rope training does not significantly change the speed rate in girls aged 9-10 years-old. They attributed the reason for this result to the fact that speed is an inherited biological factor. In contrast, Partavi [9] found that seven weeks of jump rope training improves the speed of male students aged 11 to 12 . Also, Ozer et al. [13] showed that 12-week jump rope training significantly improves the speed of girl volleyball players aged 14 to 15 .

In justifying the results of the present study, it should be stated that considering physiological differences between boys and girls, and boys' higher level of physical activity in comparison with girls in the school environment, sports clubs and outdoors, they are less likely to be affected by jump rope training course. But this intensity and duration was appropriate for girls (because of low physical activity, partly due to cultural issues, and partly due to the lack of facilities and trained personnel for woman education) and accordingly caused a change in their speed rate. Mc Lenzie [7] and Aplache (2005) [4] also found that practicing basic movement patterns and exercises during preschool improves the development of basic movement patterns and motor and sport skills in children. They stated that girls improve faster in basic motor skills than boys. Therefore, it seems that the difference between girls and boys is related to the speed performance of basic motor skills.

The results of this study also showed that jump rope trainings significantly improved agility in boys in comparison with girls. In line with this finding, Cepero et al. [5] showed that 5 months of physical education classes improve agility in 8 to 12 years-old Spanish boy students compared to girl students. They attributed the lack of improvement in girls to their low coordination which stems from their lower rates of activity. However, the improvement observed in boys in this study can be attributed to higher neuromuscular coordination and balance in comparison with girls. Because it is said that one of the important determinants of agility in men is balance. In fact, agility consists of two components of velocity and strength along with maintaining balance and coordination [27]. Boys with more muscle mass and longer bones are more likely to be stronger and faster than girls. Due to the fact that strength, speed and power are factors that affect agility, boys are more agile and girls with lower bone density and wider pelvis structure do not have good performance in running [28].

The present study showed that there is no significant difference between two groups in relation to changes in muscle endurance of shoulder girdle in jump rope training. But these exercises improved the muscular endurance of both boys and girls. In line with this result, Pavik et al. [29] showed that 3 months of swimming did not change significantly the muscular endurance of shoulder girdle in girls and boys aged 11 to 14 years. However, due to the holding of rope and the mechanism of movement of the arms and shoulders (involvement of shoulder muscles with respect to the holding and rotation of the rope), the effect of these exercises on muscular endurance in the present study was not unexpected. Therefore, in order to improve muscular endurance, one has to practice exercises that insert more-than-normal pressure on the muscles. In fact, muscle endurance only increases when the muscle works for a certain period of time, at its maximum strength and endurance, against resistances that are higher than normal. In this case, the exercise creates changes in the structure of the muscle and the nervous system, which leads to muscle hypertrophy and neural adaptation, which play roles in the development of muscular endurance [18].

The present study also showed that there is no significant difference between boys and girls in relation to the changes in 
explosive leg power in jump rope training. But within-group outcomes showed a significant improvement in the measure in both boys and girls. In line with this result, Zapartidis et al. [30] examined gender differences in male and female handball players aged 12 to 15 years old. The results indicated that there was no significant difference between girls and boys in the test of explosive power in the legs. The researchers stated that the sports special workout regimen according to the principle of specificity was the main reason for this lack of difference. But the reason for the result in the present study is that the jump rope is a stretch-contraction cycle [8]. Also, jumping rope is a lowintensity sample of plyometric exercises. Similar to plyometric exercises, jump training has two levels of eccentric contraction and rapid concentric contraction. During eccentric contraction, elastic components are drawn along when the quadriceps and gastrocnemius muscles are pulled out. Therefore, part of the energy is stored in the shape of elastic potential energy. During concentric contraction, this energy is released, resulting in increased power and speed of movement. The increase in these factors will improve the power. Additionally, the nerve coordination achieved in jump activities such as plyometric exercises and jump rope training (muscle spindle stretch reflex), is a result of increased explosive power [16].

The present study revealed that there is no significant difference between boys and girls in relation to changes of muscular power of the hands in jump rope training. But withingroup outcomes showed a significant improvement in both boys and girls. No similar research was found in order to compare the results. However, the specificity of training is probably one of the reasons for this improvement. Since the weight of the rope is significant for the elementary students, therefore, when the rope is thrown from behind to the front, there is a need for the subjects' attempt which possibly increases the power of the hands during the training period.

Another result of the present study was that there is no significant difference between two groups regarding to static balance changes in jump rope training. Within-group outcomes also showed that this index was not significantly different in boys and girls. Similar research in this area was not found, and existing researches have only been limited to one gender. For instance, Ghaderiyan et al. [31] showed that 12-week jump rope training improves the static balance in male students aged 10 to 13 years with Pes cavus. Ghelichpoor et al. [32] also found that a 10-week cycle of jump rope training would improve static balance in elementary school students. The researchers pointed to an increase in the strength of the lower limb muscles caused by participating in the training period as a result of their finding. In contrast, Fallah et al. [33] showed that 6-week jump rope training significantly improved the static balance in girls aged 14-24 with mental disorders compared to boys. The reason for this inconsistency is probably the type of subjects, the age range, and the type of test used to measure the static balance (The Sharpened or Tandem Romberg test). But the reason for the result of this study is that, since jump rope training is a dynamic activity and includes repeated jumps, the principle of specificity for static balance is not regarded here. In addition, the short duration of the training period ( 6 weeks) cause the index not to be heavily affected. Perhaps, if the training period was conducted for a longer term, we would have different results.

The present study also found that there was no significant difference between boys and girls in relation to dynamic balance changes in jump rope training. But within-group outcomes showed a significant improvement in both boys and girls. Similar research has not been found in this area, and existing researches have only been carried out on one gender. In this regard, Nicklson [34] showed that 24 weeks jump rope training significantly improves dynamic balance in boys aged 5-14 years old. Brararzade et al. [14] also demonstrated a dynamic balance improvement based on a 6-week speed jump rope training in fourth-grade elementary school students. In another study, Sohrabi Jahromi, Gholami [16], stated that performing 15-week jump rope training improves the dynamic balance of girls aged 9-10 years old. In justifying these results, it can be said that in the jump rope training, more stress is applied to neuromuscular systems in order to maintain balance, also, while exercising, the individual needs dynamic balance. Therefore, jump rope training is a special exercise to improve dynamic balance and due to repeated jumps and keeping balance while performing these movements, it matches with the principle of the specificity of training. Therefore, achieving this result should not be unexpected.

The results of this study showed that there is no significant difference between boys and girls in relation to weight changes. Also, within-group outcomes revealed that this index did not change significantly in both boys and girls. In this regard, Chen (2010) [35], Chao-Chien, Yachan [36], in two separate studies, showed that jump rope had no significant effect on body mass index and weight of blind and mentally impaired teens. They did not have a diet and did not control the intensity of exercise because of the physical limitations of subjects and also stated it as the reason for their results. In contrast, Sheikholeslami Vatani et al. [15] showed that 8-week jump rope training improves waist-hip ratio and fat percentage in obese boys. The reason for the difference in the results of the research with the present study is the difference in the type of exercise program and the type of subjects. But the reason for the outcome of the current study can be attributed to the duration of the training period and the duration of each training session, which was not able to stimulate changes in body weight. In addition, the lack of diet control probably affects this outcome. So that food intake by subjects during the training may increase, which causes no significant changes in body weight.

\section{Conclusion}

It is recommended that elementary school girls and boys use jump rope exercises to improve their physical and motor fitness. 


\section{References}

1. Pate RR, Wang CY, Dowda M, Farrell SW, O Neill JR (2006) Cardiorespiratory fitness levels among US youth 12 to 19 years of age: findings from the 1999-2002 National Health and Nutrition Examination Survey. Arch Pediatr Adolesc Med 160(10): 1005-1012.

2. Makiani M, Shetab Bushehry SN, Ramezani P (2011) The effect of rope on the Perceptual-Motor abilities of female students in third grade elementary. Sixth National Conference on Physical Education and Sport Sciences students, Tehran, Iran.

3. Campbell G (1987) Interval training with a rope (fun jump). Science and Sports pp. 201-209.

4. Aplache RP (2005) Activity-based intervention in motor skill development. Perceptual and motor skills 100(3): 1011-1120.

5. Cepero M, López R, Suárez Llorca C, Cabrera A (2011) Fitness test profiles in children aged 8 - 12 years old in Granada (Spain). Journal of Human Sport \& Exercise 6(1): 135-145.

6. Doris H (2001) Aerobic Responses of 9-10 year old Children to Rope Jumping. Thesis, University of Hong Kong, China.

7. Mc Lenzie TL (2002) Childhood movement skills: predictors of physical activity in Angle american and Mexican American adolescents? Research quarterly for exercise and sport 73(3): 238- 244.

8. Miyaguchi K, Demura SH, Omoya M (2015) Relationship between jump rope double unders and sprint performance in elementary schoolchildren. Journal of Strength and Conditioning Research 29(11): 3229-3233.

9. Partavi S (2013) Effects of 7 weeks of rope jump training on cardiovascular endurance, speed, and agility in middle school student boys. Sport Science 6(2): 40-43.

10. Wiliams SM (2010) Physical activity levels in coed and same-sex physical education using the tactical games model. Department of Exercise and Sport Science. The University of Utah, pp. 172.

11. Chu M, Lee MH (2013) Comparison of body composition of college students after 4-week jump-roping exercise. Journal of The Korean Society of Physical Medicine 8(4): 627-635.

12. Duzgun I, Baltaci G, Colakoglu F (2010) The effects of jump-rope training on shoulder isokinetic strength in adolescent volleyball players. Journal of Sport Rehabilitation 19(2): 184-199.

13. Ozer D, Duzgun I, Baltaci G, Karacan S, Colakoglu F (2011) The effects of rope or weighted rope jump training on strength, coordination and proprioception in adolescent female volleyball players. The Journal of sports medicine and physical fitness 51(2): 211-219.

14. Brararzade Grivedihi M, Npurbakhsh P, Sepasi H (2014) Effects of Speedy and demonstration jumping-rope training on gross motor skills. Trends in life science 3(4): 321-327.

15. Sheikholeslami Vatani D, Jahani N (2015) The effect of rope training on physical fitness parameters in 9-12 years old overweight/obese boys. Journal of Practical Studies of Biosciences in Sport 2(3): 60-71.

16. Sohrabi Jahromi M, Gholami M (2015) The effect of jump-rope training on the Physical fitness of 9 to 10 years old female students. Advances in Applied Science Research 6(4): 135-140.

17. Matsuzaka A, Takahashi Y, Yamazo M, Kumakura N, Ikeda A, et al. (2004) Validity of the multistage 20-m shuttle-run test for Japanese children adolescents, and adults. Pediatric Exercise Science 16(2): 113-125.

18. Gaieeni AA, Rajabi H (208) Physical fitness. SAMT Publication p. 255.

19. Gharakhanlou R, Kordi MR, Gaeeini AA, Alizadeh MH, Vaezmousavi MK (2012) Tests for assessing physical fitness, skill and psychological of elite athletes from different sports disciplines. Asre Entezar Puplication pp. 72.

20. Hooper TL, James CR, Brismée JM, Rogers TJ, Gilbert KK, et al. (2016) Dynamic balance as measured by the Y-Balance Test is reduced in individuals with low back pain: A cross-sectional comparative study. Physical Therapy in Sport 22: 29-34.

21. Rowland TW (1985) Aerobic response to endurance training in prepubescent children: a critical analysis. Medicine \& Science in Sports \& Exercise 17(5): 493-497.

22. Obert B, Mandigouts S, Nottin S, Vinet A, N Guyen L, et al. (2003) Cardiovascular responses to endurance training in children: Effect of gender. European Journal of Clinical Investigation 33(3): 199-208.

23. Artero EG, España Romero V, Ortega FB, Jiménez Pavón D, Ruiz JR, et al. (2010) Health-related fitness in adolescents: Underweight, and not only overweight, as an influencing factor; The AVENA study. Scandinavian Journal of Medical Science in Sports 20(3): 418-427.

24. Williford HN, Duey WJ, Olson MS (1996) The relationship between fire fighter physical fitness and performance. Medicine \& Science in Sports \& Exercise 28(5): S198.

25. Bovet P, Auguste R, Burdette H (2007) Strong inverse association between physical fitness and overweight in adolescents: A large school-based survey. The International Journal of Behavioral Nutrition and Physical Activity 4: 24-31.

26. Ozcelik O, Aslan M, Ayar A, Kelestimur H (2004) Effects of body mass index on maximal work production capacity and aerobic fitness during incremental exercise. Physiological research 53: 165-170.

27. Ravasi A, Gaeini A, Tasmeh M, Abdi H, Abdolmohammadi A (2015) The effect of plyometric, strength and complex training on agility of young free style Wrestlers in Ilam city. Journal of Sport Biosciences 6(2): 191204.

28. Sims EL, Hardaker WM, Queen RM (2008) Gender differences in plantar loading during three soccerspecific tasks. British Journal of Sports Medicine 42(4): 272-277.

29. Pavik R, Trninik V, Katic R (2008) Sex differences in motor characteristics of elementary school children included/not included in swimming training. Collegium antropologicum Coll 32(3): 829-834.

30. Zapartidis I, Nikolaidou M, Vareltzis I, Kororos P (2011) Sex differences in the motor abilities of young male and female handball players. Biology of Sport 28(3): 3-8.

31. Ghaderiyan M, Ghasemi GH, Zolaktaf V (2016) Effect of rope jumping exercise on foot arch in boy students with cavus, planus, and normal foot types. Bimontly Journal of Research in Rehabilitation sciences 11(3): 207-218.

32. Ghelichpoor B, Shahbazi M, Bagherzadeh F (2013) The effect of rope jumping national plan on eye- hand coordination in fourth grade elementary school students. Journal of Development and Motor Learning 5(4): 57-69.

33. Fallah F, Sokhanguei Y, Rahimi A (2014) The effect of jumping rope training on static balance in male and female students with intellectual impairment. European Journal of Experimental Biology 4(1): 137-141.

34. Nicklson MS (2005) Jumping Through Summer: Challenges Of Starting a Jump Rope Program. Florida Public Health Review 2: 60-62.

35. Chen H (2010) The effects of rope skipping on health-related physical fitness in student with mild intellectual disability: A case study. Unpublished Master's Thesis. National Taiwan Normal, Taipei, China.

36. Chao Chien C, Yi Chun L (2012) Jumping rope intervention on healthrelated physical fitness in students with intellectual impairment. The journal of human resource and adult learning 8(1): 56-62. 
This work is licensed under Creative Commons Attribution 4.0 License

DOI: 10.19080/JPFMTS.2018.03.555610
Your next submission with Juniper Publishers will reach you the below assets

- Quality Editorial service

- Swift Peer Review

- Reprints availability

- E-prints Service

- Manuscript Podcast for convenient understanding

- Global attainment for your research

- Manuscript accessibility in different formats ( Pdf, E-pub, Full Text, Audio)

- Unceasing customer service

Track the below URL for one-step submission https://juniperpublishers.com/online-submission.php 